\title{
Industrial Revolution 5.0 and the Role of Cutting Edge Technologies
}

\author{
Mamoona Humayun \\ Department of Information Systems \\ College of Computer and Information Sciences, Jouf University \\ Al-Jouf, Saudi Arabia
}

\begin{abstract}
IR 4.0 emphasizes the interconnection of machines and systems to achieve optimal performance and productivity gains. IR 5.0 is said to take it a step further by fine-tuning the human-machine connection. IR $\mathbf{5 . 0}$ is more collaboration between the two: automated technology's ultra-fast accuracy combines with a human's intelligence and creativity. The driving force behind IR 5.0 is customer demand for customization and personalization, necessitating a greater human involvement in the production process. As IR 5.0 evolves, we may expect to see a slew of breakthroughs across various industries. However, just automating jobs or digitizing processes will not be enough; the finest and most successful businesses will be those that can combine the dual powers of technology and human ingenuity. IR 5.0 focuses on the use of modern cutting-edge technologies, namely, AI, IoT, big data, cloud computing, Blockchain, Digital twins, edge computing, collaborative robots, and 6G along with leveraging human creativity and intelligence. Wherever possible, IR 5.0 will change industrial processes worldwide by removing mundane, filthy, and repetitive activities from human workers. Intelligent robotics and systems will have unparalleled access to industrial supply networks and production floors. However, to understand and leverage the benefits of IR 5.0 better, there is a need to understand the role of modern CET in industrial revolution 5.0. To fill this gap, this article will examine IR 5.0 prospective, uses, supporting technologies, opportunities, and issues involved that need to be understood for leveraging the potentials of IR 5.0.
\end{abstract}

Keywords-Industry 5.0; cutting-edge technologies; Internet of Things; Aartificial intelligence; big data

\section{INTRODUCTION}

From the industrial revolution to the digital transformation and beyond [1-3], the history of the IR traces the progress of the manufacturing industry. Each stage indicates a shift in the production process that has altered how we think about and operate in the business. When the major method of manufacturing shifted from people to machine power, the first IR began. The second IR, known as the Technological Revolution or IR 2.0, continued where the first left off, with improved electrical technology allowing for even more manufacturing and more complex machinery. The third IR, known as the digital revolution or IR 3.0, began with the invention of the first computers, which created the foundation for a society that is difficult to envision today without computer technology. We are currently in IR 4.0, which is defined by the amount of automation that has been accomplished. Machines can frequently govern themselves in many ways utilizing internet technology or the IoT. IR 4.0 also emphasizes the utilization of cloud technologies and the relevance of BGD. Although IR 4.0 has greatly improved the manufacturing industry by enabling security, scalability, control and visibility, customer happiness, and customization, the human drive for creativity still exists, and researchers are already predicting the next revolution that is IR 5.0 [4-6]. In short, if the current revolution focuses on converting factories into IoT-enabled smart facilities, IR 5.0 is expected to place a greater emphasis on the return of human skills and intelligence to the industrial framework. Fig. 1 illustrates all the IRs so far diagrammatically.

According to [7-9]; in IR 5.0, man and machine work together to optimize manufacturing process performance. Surprisingly, the fifth IR may already be underway among firms that are only starting to use IR 4.0 concepts. The reason for this is that when businesses adopt contemporary technology, they do not suddenly eliminate huge segments of their employees and shift to a fully automated operation. Thus, by delegating repetitive and boring activities to robots/machines and critical thinking tasks to people, IR 5.0 improves manufacturing quality. IR 5.0 supports more skilled occupations than IR 4.0 because experts handle the machines. Further, it focuses on improving consumer happiness by forming a collaborative relationship between humans and robots. Another advantage of IR 5.0 as mentioned by [10, 11] is that it provides greener solutions than traditional industrial transformations, which do not prioritize environmental protection.

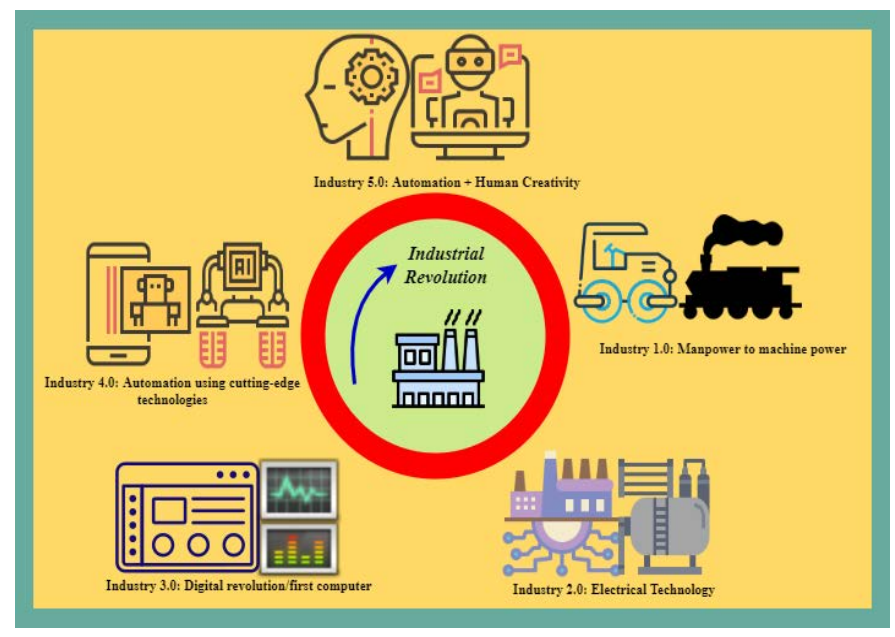

Fig. 1. Industrial Revolution. 
Several current studies examine the enabling technologies (ETs), applications, and problems of prior industrial standards and supporting industrial technologies such as articles [10-15]. The authors of [14], for example, investigate the ETs of the IR 4.0 standard as well as the rationale for their inclusion in the standard. Simultaneously, [15] examines the ETs in the Web of Science database for IR 4.0, as well as the contributions of several forerunners in the development of this database. The authors of [16] have published a comprehensive review of the ETs and uses of virtual reality in IoT systems.

Industries can play an important role in addressing societal challenges such as resource preservation, climate change, and social stability. Businesses, employees, and society all benefit from IR 5.0. In addition to giving workers more control, it meets the ever-changing needs of employees in terms of skills and training. Competitiveness is boosted, and top talent can be attracted more easily. It is beneficial to our world since it encourages circular production models and supports technologies that increase the efficiency of natural resource utilization. Even though IR 5.0 is becoming more popular, we are unaware of any study that analyzes the role of modern CET in the revolution of IR 5.0. As a result of this observation, we intend to present the role of modern CET in the IR in the context of IR 5.0. In a nutshell, our work's contributions may be stated as follows:

1) Define IR 5.0 to have a comprehensive knowledge of the concept from several angles.

2) Comparing and contrasting IR 5.0 to earlier IR.

3) Discuss the most promising IR 5.0 applications

4) Discuss the role of modern CET in IR 5.0

5) Issues and challenges involved in IR 5.0

TABLE I. LIST OF ABBREVIATIONS USED

\begin{tabular}{|l|l|}
\hline Abbreviations & Used for \\
\hline CET & Cutting Edge Technologies \\
\hline IoT & Internet of Things \\
\hline AI & Artificial intelligence \\
\hline BGD & Big Data \\
\hline DT & Digital Twins \\
\hline IR & Industrial Revolution \\
\hline SCM & Supply Chain Management \\
\hline BCT & Blockchain Technology \\
\hline CPPS & Cyber Physical Production Systems \\
\hline CAGR & Compound Annual Growth Rate \\
\hline ITU & International Telecommunication Union \\
\hline ZB & Zettabytes \\
\hline CC & Cloud Computing \\
\hline COBOTS & Collaboration Robots \\
\hline ETs & Enabling Technologies \\
\hline EC & Edge Computing \\
\hline SME & Small and Medium size Organizations \\
\hline & \\
\hline
\end{tabular}

www.ijacsa.thesai.org
The remaining paper is structured as: Section 2 will define IR 5.0 from various perspectives. Section 3 will summarize existing knowledge to compare and contrast IR 5.0 to the earlier IR. Section 4 will discuss the key applications of IR 5.0. Section 5 will highlight the role of modern CET in the fifth IR. Section 6 will discuss the associated issues and challenges. Section 7 will discuss the findings of the study. Finally, Section 7 will wrap up the paper by providing the conclusion of the paper and insights into future work.

Table I shows the list of abbreviations used in this research for better understanding.

\section{LITERATURE REVIEW}

This section will provide a general overview of IR 5.0 to provide a better understanding of the phenomenon. Further, it will also discuss the key pillars of IR 5.0.

\section{A. IR 5.0 and State-of-the-Art}

Since IR 5.0 is still evolving, several researchers and practitioners have presented varied definitions. Here are some of the definitions that are considered.

Definition1: By integrating work processes and intelligent systems, IR 5.0 brings the human workforce back to the factory, where humans and machines are partnered to boost process efficiency by harnessing human intelligence and creativity [4].

Definition2: IR 5.0 blends the inherent strengths of human intelligence and CPPS to build synergetic factories. In addition, authorities are searching for creative, ethical, and humancentered design to overcome the personnel shortages caused by IR 4.0 [17].

Definition3: IR 5.0 is a paradigm for the next phase of industrialization, which incorporates the return of labor to factories, distributed production, intelligent SCM, and hyper customization, all of which work together to create a tailored customer experience over time [18].

\section{B. Pillars of IR 5.0}

IR 5.0 focuses on stakeholder value rather than shareholder value, reinforcing the industry's role and contribution to society. Below are the key pillars of IR 5.0 (as shown in Fig. 2).

1) Human-centric: Human ingenuity and craftsmanship are combined with the speed, efficiency, and consistency of robots in IR 5.0. Thus it promotes human empowerment, talent, and diversity [4].

2) Sustainability: Additive manufacturing, often known as $3 \mathrm{D}$ printing, is one of the most notable elements of IR 5.0, and it is used to make manufacturing items more sustainable. In IR 5.0, additive manufacturing aimed to improve customer happiness by incorporating benefits into goods and services [19]. 


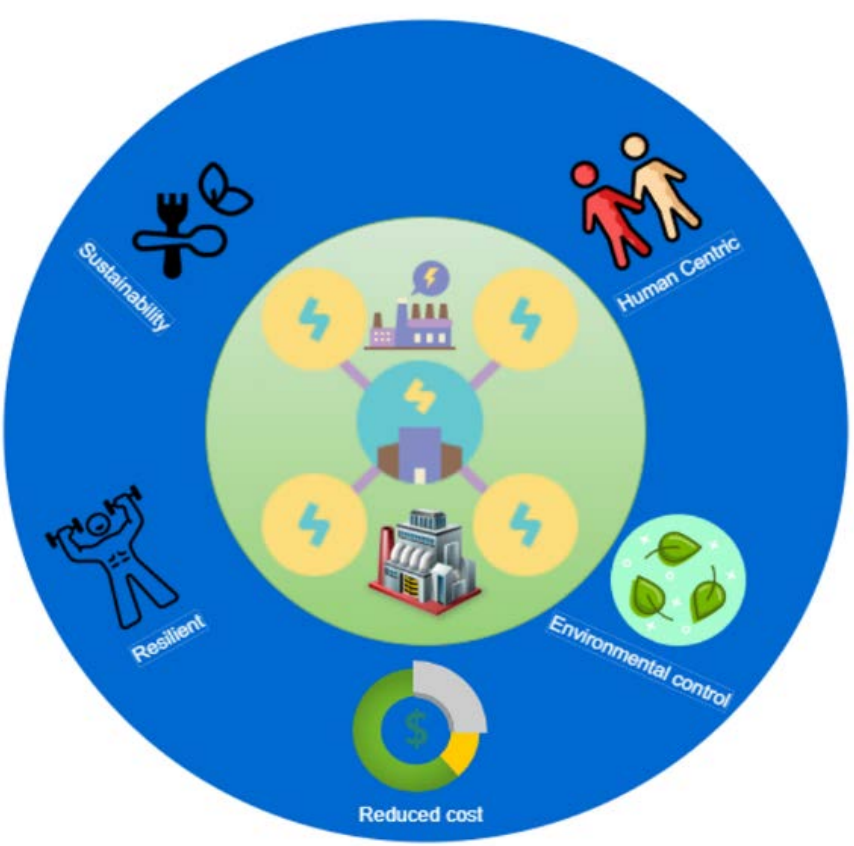

Fig. 2. Pillars of IR 5.0.

3) Resilient: The term "resilience" refers to the necessity to improve industrial production's robustness, equipping it better against interruptions and ensuring that it can offer and sustain key infrastructure during the crisis. High resilience can be attained when humans and robots operate together [20, 21].

4) Reduced cost and environmental control: Climate, humidity, temperature, and energy usage are all monitored in real-time and predicted using smart, networked sensors and specialized algorithms. This is especially beneficial in farms that are highly dependent on the weather. Knowing what to expect and where to act might help to avoid costly mistakes and boost the output [22].

\section{Opportunities of IR 5.0}

The prospects presented by IR 5.0 are as follows, these opportunities are discussed in the articles [8,23-26].

1) Better employment: Through the implementation of next-generation technologies, greater automation will have a favorable influence on employment in several areas.

2) Customization: Customers have more customization options with highly automated production methods.

3) Improved human efficiency: IR 5.0 opens up more options for creative individuals to come and work, allowing for improved human efficiency.

4) Employee safety: Employee safety on the work floor has improved since COBOTs can do hazardous tasks.

5) Customer satisfaction: More personalized products and services boost consumer happiness, loyalty, and attract new customers, resulting in higher profits and market share for businesses.

6) Better opportunities: It gives start-ups and entrepreneurs in creative and inventive fields, enormous opportunities to develop new goods and services related to IR 5.0, as long as enough money and infrastructure are available.

7) Human-machine interaction: IR 5.0 places a greater emphasis on human-machine interaction and gives a bigger platform for research and development in this industry.

8) Quality Service: With the support of IR 5.0, quality services may be offered in faraway regions, particularly in the healthcare business, such as surgical procedures performed by robots in rural areas.

9) Frequent follow-up: IR 5.0 will assist the customer digitally in handling frequent follow-up assignments by making machines adaptable according to employee demands.

10)Higher-value job: Because individuals are given the freedom to be responsible for building again, IR 5.0 provides higher-value jobs than before.

11)Better planning: In IR 5.0, the production cell operator is more involved in the planning approach than the more or less automated manufacturing method.

12) Creative freedom: It enables more custom-made and personalized items, as well as creative freedom.

13)Automation: With IR 5.0, it is easier to automate production processes.

In comparison to IR 4.0, the preceding discussion demonstrates that IR 5.0 is the next industrial revolution, in which human specialists and efficient, intelligent, and precise machines will work together to develop efficient and userfriendly manufacturing solutions. It will enhance the sector by bringing in human talents and competencies, as well as opening up new opportunities. We will further explore the strengths of IR 5.0 and the role of modern CET in IR 5.0 in the upcoming sections.

\section{COMPARISON OF IR 4.0 AND 5.0}

To better understand and visualize the benefits of IR 5.0, it's important to comprehend and see the differences between IR 4.0 and 5.0. This section will compare both of these IRs.

Today, we live in IR 4.0, which is rapidly evolving towards IR 5.0. The fourth IR, often known as IR 4.0, was constructed on top of the third to allow improved technology. Everything became "Smarter" during this period. IoT, CC, CPPS, and cognitive computing were among the most essential technologies discussed. IR 4.0 connects systems, components, and humans over a network as discussed in [27-30], making the production process more efficient and automated. Humans collaborating with these technologies to improve efficiency is the goal of the fifth Revolution, often known as IR 5.0. For optimal advantages, it is vital to strategize techniques of human-robot integration since it will seek to match the rising demand for individuals with unique customization and modifications. Improved human engagement with intelligent machines will lead to increased efficiency. Not to mention that, as a result of this shift, more high-paying positions will be created. Table II summarizes the comparison between IR 4.0 and 5.0 so that organizations could leverage the benefits of IR 5.0. 
TABLE II. COMPARISON BETWEEN IR 4.0 AND 5.0

\begin{tabular}{|l|l|}
\hline Industry $\mathbf{4 . 0}$ & Industry $\mathbf{5 . 0}$ \\
\hline The goal is to automate processes. & $\begin{array}{l}\text { The goal is to strike a balance } \\
\text { between machine and human } \\
\text { engagement. }\end{array}$ \\
\hline $\begin{array}{l}\text { The most crucial factor was } \\
\text { technology }\end{array}$ & $\begin{array}{l}\text { The most crucial collaboration is } \\
\text { between people and robots. }\end{array}$ \\
\hline The entire environment is virtual. & The shift back to the real world. \\
\hline $\begin{array}{l}\text { As new smart technologies were } \\
\text { adopted, the number of personnel } \\
\text { was reduced. }\end{array}$ & $\begin{array}{l}\text { An increase in the number of people } \\
\text { who come into contact with machines. }\end{array}$ \\
\hline $\begin{array}{l}\text { Machines that are smarter and } \\
\text { more linked to the workplace. }\end{array}$ & $\begin{array}{l}\text { Cognitive computers and human } \\
\text { intelligence are being combined. }\end{array}$ \\
\hline $\begin{array}{l}\text { There is no way to personalize or } \\
\text { customize the product. }\end{array}$ & $\begin{array}{l}\text { Personalization and customization are } \\
\text { available, allowing each product to be } \\
\text { improved and tailored to the needs of } \\
\text { the person. }\end{array}$ \\
\hline $\begin{array}{l}\text { It's still tossing back and forth } \\
\text { notween renewable and }\end{array}$ & $\begin{array}{l}\text { It is more environmentally friendly } \\
\text { since renewable energy sources will } \\
\text { be used more often. }\end{array}$ \\
\hline
\end{tabular}

\section{IR 5.0 APPLICATIONS}

IR 5.0 is already in use in various areas, including healthcare, manufacturing, CPPS, SCM, education, disaster management, and so on, as mentioned in studies [23, 26, 31]. In addition to merging many CET with machines, such as AI, edge computing (EC), IoT, DT, COBOTS, 6G and beyond, BGD analytics, and so on, the intellect of people is also utilized when making judgments in IR 5.0. As a result, the personal human touch is added to the IR 4.0 pillars of efficiency and automation. Below we provide some core applications of IR 5.0.

\section{A. IR 5.0 in Healthcare}

IR 5.0 has the potential to revolutionize the healthcare industry [33], allowing for the production of individualized gadgets, implants, and other medical products. Routine occupations, such as routine checkups conducted by doctors, can be handled by COBOTS under IR 5.0. Similarly, humanrobot collaboration can enhance the diagnosis and treatment process. Intelligent wearable gadgets, such as smartwatches and intelligent sensors, can, for example, continuously capture a patient's healthcare data in real-time and store it in the cloud [32]. The patients' medical condition may then be diagnosed using machine learning methods. These intelligent gadgets can interact with one another, and if a doctor's attention is necessary, these devices can feed the present state of the patient to the physicians and notify them to treat the patient. Doctors can use COBOTS to get assistance from robots that can interact with one another to perform surgery on patients.

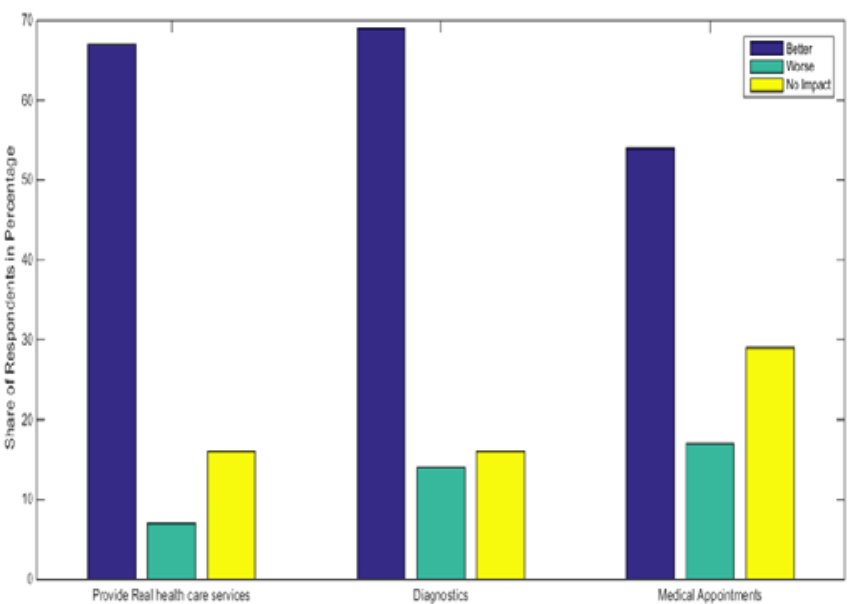

Fig. 3. Canadians' Predictions on the Influence of AI in Healthcare over the Next Ten Years, as of 2019[34].

In a poll conducted in Canada to assess the role of AI and robots in healthcare, approximately $70 \%$ of respondents said that AI programs or robots delivering genuine health care services, such as robot-aided surgery, early diagnosis, and so on, will make life better. As of August 2019, the data in Fig. 3 depicts Canadians' projections for AI-related health developments in the next ten years and their influence on life. Statista was used to compile the data for this research.

\section{B. IR 5.0 in Manufacturing/Production}

According to the co-founder of universal robots chief technology [35], IR 5.0 will transform the factory into a place where creative individuals can come and work, resulting in a more customized and human experience for both workers and consumers. The fifth IR will see substantially more complicated collaborative interactions between intellectuals, machinery, processes, and overall system for optimal performance optimization.

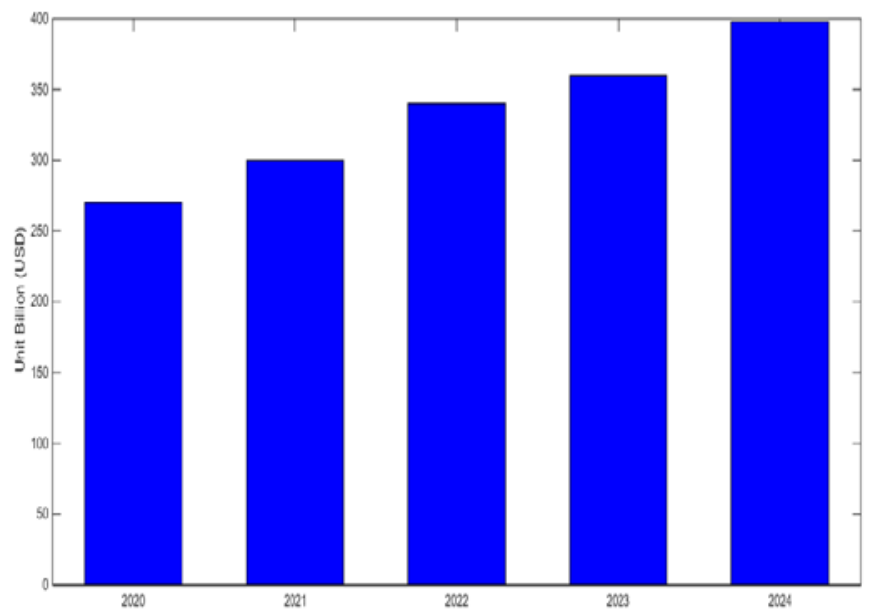

Fig. 4. Revenue of Global Manufacturing Industry. 
According to the TrendForce investigation [36], as shown in Fig. 4, the manufacturing industry's income is predicted to improve in the near future owing to human and robot collaboration. This shows that the fifth IR might lead to paradigm shifts and profound changes in how we think about industry and production.

\section{IR 5.0 and Supply Chain Management}

IR 5.0 is expected to optimize the SCM by combining smart, linked digital environments with the human intelligence required to maximize their value. According to $\mathrm{KBV}$ research statistics [37], as shown in Fig. 5, the global SCM software market is estimated to reach $\$ 22.7$ billion by 2024, growing at a 12.1 percent CAGR. SCM Software is a real-time analytical tool for managing the movement of products and other types of data throughout the SCM network. The software improves an organization's supply chain operations.

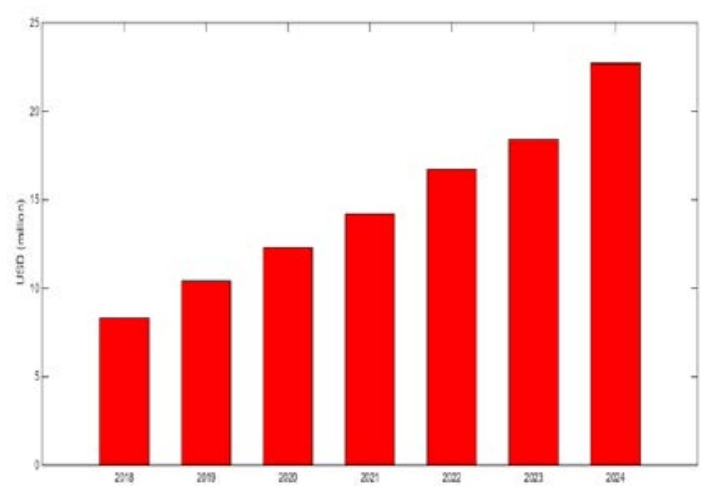

Fig. 5. Global SCM Software Market.

IR 5.0 will improve SCM in the following way [38]

- Increasing supply chain customization improves not just customer happiness but also efficiency and profits.

- Using more up-to-date data, reducing supply chain risks and waste.

- allowing supply chain and logistics units to spend more time on strategic innovation rather than putting out fires or dealing with fundamental execution issues.

- Improving supply chain integration to form more strategic alliances.

- Increasing the value of an organization's human capital by assisting in retaining and transferring knowledge about the features of a certain supply chain.

\section{IR 5.0 and Education}

IR 5.0 will also transform education [39, 40], the current education is fueled by information, and if it can be trained and equipped with digitally smart machines, or COBOTS, that are further supplemented with the human touch, it will take society along the path of personalized education. As a result, COBOTS will help to develop a human-centric society, which will be strengthened by human wisdom, enabling education 5.0, tailored education for everybody. Humans will be aided by many functioning COBOTS to assist them with day-to-day tasks and support their personal and professional development.

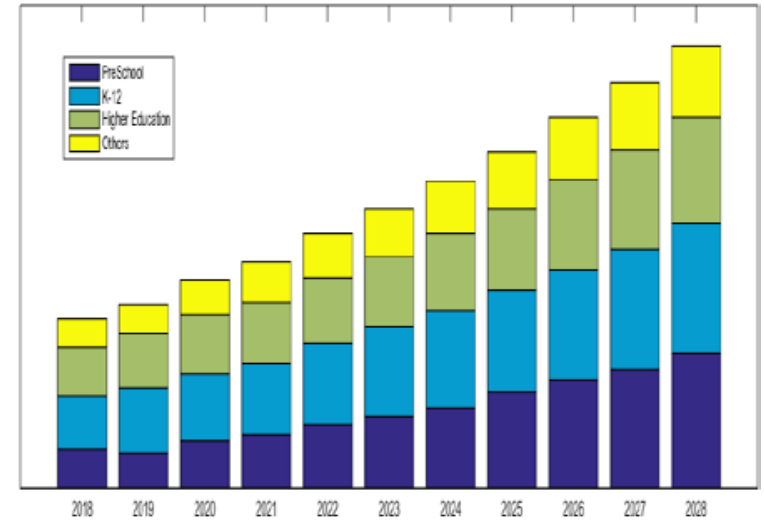

Fig. 6. Education Technology Market (Asia Pacific).

The worldwide education technology industry is expected to be worth USD 89.49 billion in 2020 [41], with a CAGR of 19.9\% predicted between 2021 and 2028 as shown in Fig. 6 . This shows that a blend of digital technology and human intelligence has the potential to expand educational opportunities.

\section{Role OF CET IN THE ReVOlution OF IR 5.0}

Edge computing, IoT, DT, Blockchain, BGD analytics, COBOTS, and 6G are just a few of the CET that, when combined with cognitive abilities and creativity, may help enterprises enhance output and offer customized goods more rapidly. IR 5.0 is an improved manufacturing model that focuses on the collaboration between humans and robots, and this collaboration makes human talents more productive and easier to automate for individuals and enterprises than they have ever been. According to the statistics provided by Statista in [42], as of 2020, new CET are projected to have the largest influence on businesses all around the world as shown in Fig. 7. The data of Fig. 7 shows that IoT is widely considered as one of the most crucial areas of current and future technology, the second CET that highly impacted organizations worldwide is AI robots, nearly used in every field to increase efficiency and complement our human skills [22]. Fig. 7 depicts the other CET that have had a significant influence on the global organization. Now we'll talk about how contemporary CET will play a part in the fifth IR.

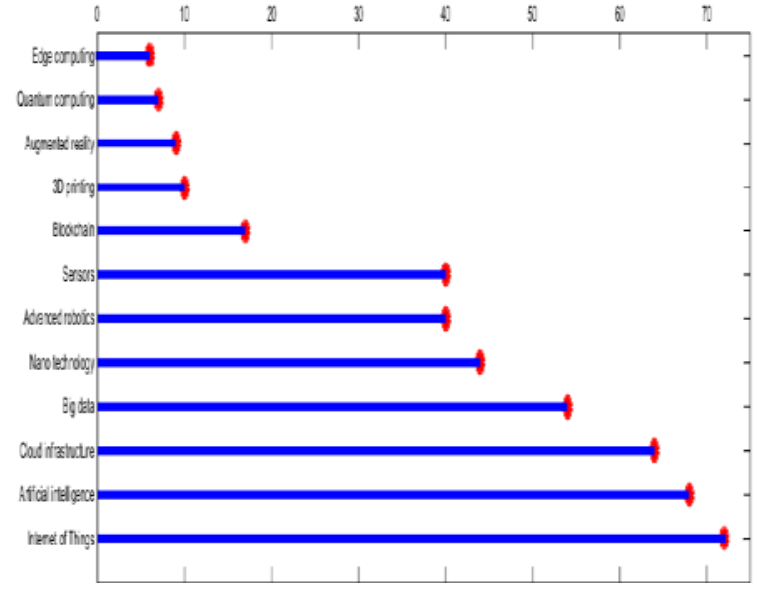

Fig. 7. CET Impact on Organizations Globally as of 2020. 


\section{A. IoT and IR 5.0}

Humans define the strategy, give supervision, and contribute creative input in IR 5.0, while technology does the dull, repetitive, and error-prone activities. Businesses will benefit from this new division of labor not only in terms of cost savings but also in terms of tapping into new value streams provided by the human touch. The IoT is defined by two characteristics: automation and connection [43]. Given these characteristics, the IoT will need to leverage a variety of technologies to guarantee that data is sent, analyzed, and responded automatically across different devices. The IoT has changed the modern world and is a primary driver of the fifth IR [44]. The following are some of the most important advantages of IoT in terms of industrial advancement [45].

- Increased employee productivity and decreased human labor

- Effective management of operations

- Optimum utilization of resources and assets

- Cost-effective operation

- Workplace safety has improved.

- Marketing and business growth that is thorough

- Customer retention and service have improved.

- Better business prospects

- The company's image will be more trustworthy.

Because of IoT's widespread use and benefits, the number of IoT-connected devices is fast growing and is projected to continue to grow in the near future, as shown in Fig. 8. The data of Fig. 8 is taken from [46].

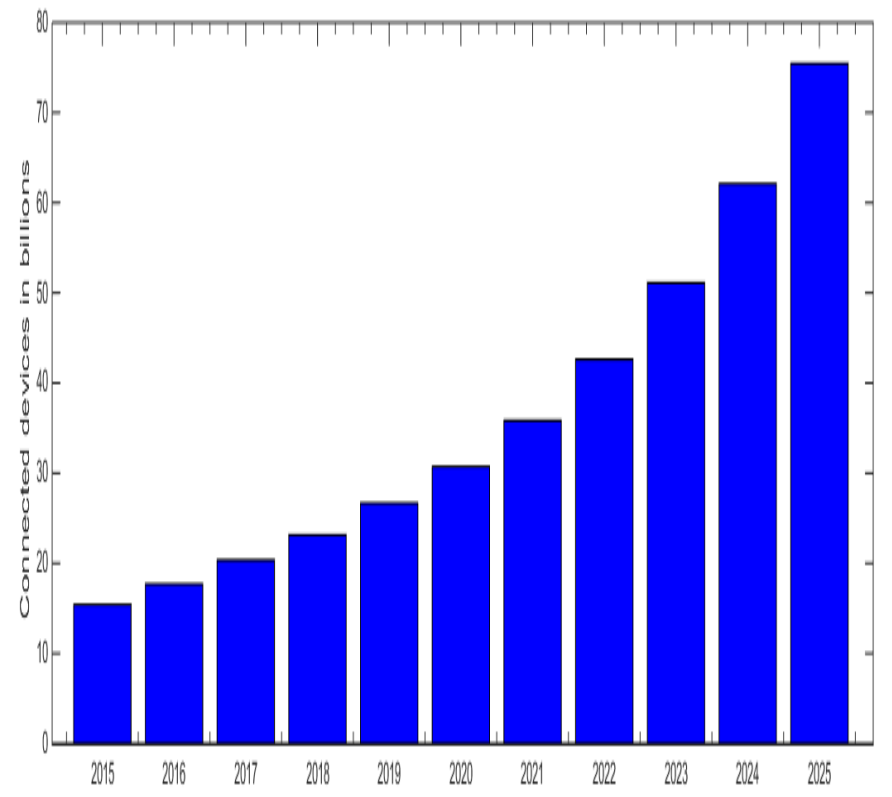

Fig. 8. Expected IoT Connected Devices Worldwide.

\section{B. Cloud Computing and IR 5.0}

$\mathrm{CC}$ is a concept that allows for the instantaneous leasing of computer resources with little or no communication with the provider. Cloud simplifies operations in this sense since it eliminates the need for rigorous resource dimensioning and planning, allowing for flexible usage without the user's previous commitment [47, 48]. Cloud users benefit from almost all the resources they need, and they may either utilize or supply everything as a service.

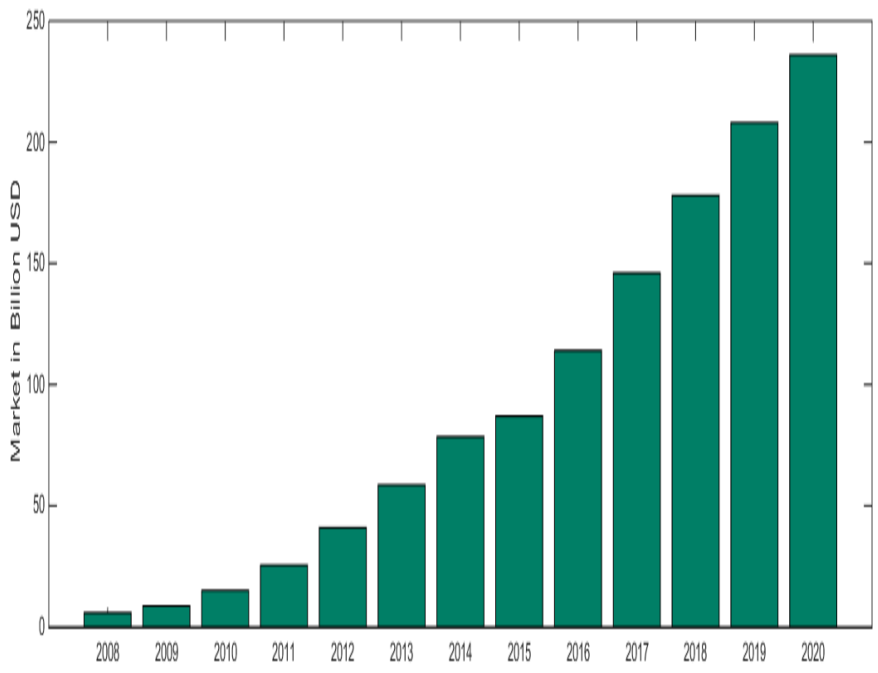

Fig. 9. Global Public Cloud Market Size Worldwide.

Cloud, in particular, is required to reap the benefits of IR 5.0 since it provides user mobility, distributed data analytics, resources' heterogeneity, and meets the needs of diverse applications with low latency. It also makes managing and developing computation, storage, and networking services easier between data centers and end devices. It's also a strong tool for processing BGD generated through IoT sensors, allowing IR 5.0 to realize its full potential [20, 47, 49]. Due to these potential benefits, the cloud market has grown at a tremendous pace as shown in Fig. 9. The statistics of Fig. 9 are taken from [50].

\section{BGD and IR 5.0}

In the realm of IR 5.0, BGD Analytics is expected to play a significant role. Some firms in IR 5.0 can utilize BGD Analytics to better understand customer behavior to optimize product pricing, improve manufacturing efficiency, and lower overhead expenses [51]. IR 5.0 apps can leverage BGD Analytics to make real-time choices to improve their competitive edge, with an emphasis on offering suggestions on predictive findings for significant events and customization [52]. Manufacturers can create and handle large amounts of data with the support of real-time analytical data. Another important problem in IR 5.0 is continuous process improvement, which frequently necessitates the collection of extensive data on the whole production cycle. To enhance predictability and explore new possibilities, BGD analytics approaches are utilized to identify and eliminate non-essentials. According to [53], the revenue from the BGD industry is growing and is likely to continue to grow in the future as shown in Fig. 10. 


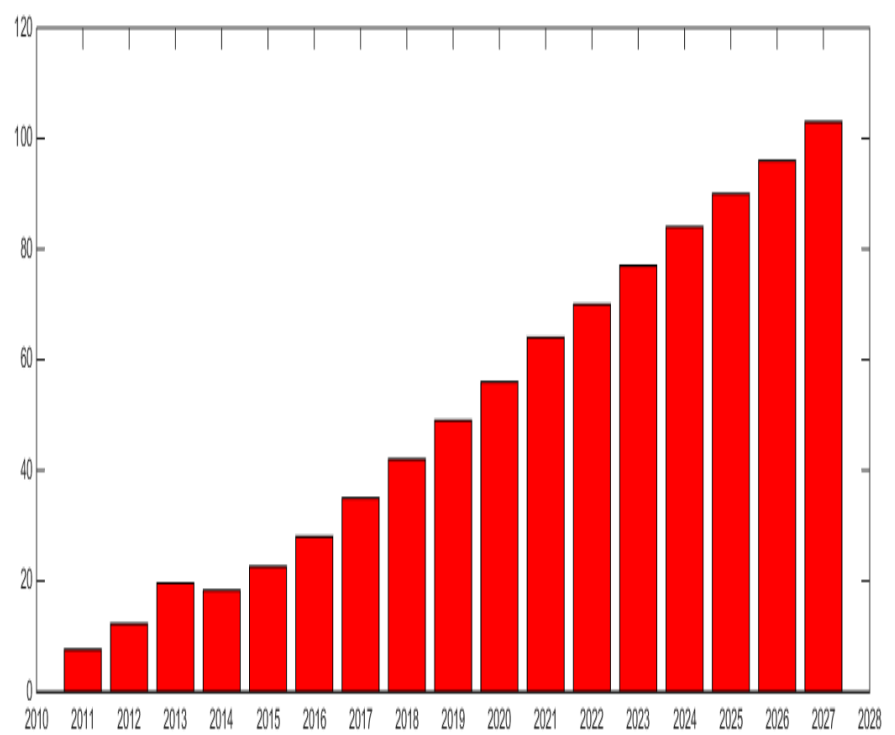

Fig. 10. Revenue Prediction for the Global BGD Market from 2011 to 2027.

\section{Digital Twins and IR 5.0}

DT can provide significant value to the creation of customized items on the market, improve business operations, fewer faults, and fast increase creative business models to make profits in IR 5.0. The DT may help IR 5.0 address technical challenges by finding them earlier, identifying configurable components, generating more accurate projections, forecasting future failures, and preventing enormous financial losses [54]. This form of smart architectural design enables businesses to get economic benefits more rapidly and sequentially than ever before. DT can be used for the access of real-time data and creating simulation models in IR 5.0, allowing organizations to edit and update physical things remotely. DT is also used in IR 5.0 for customization that allows clients to build virtual environments to realize the findings [55].

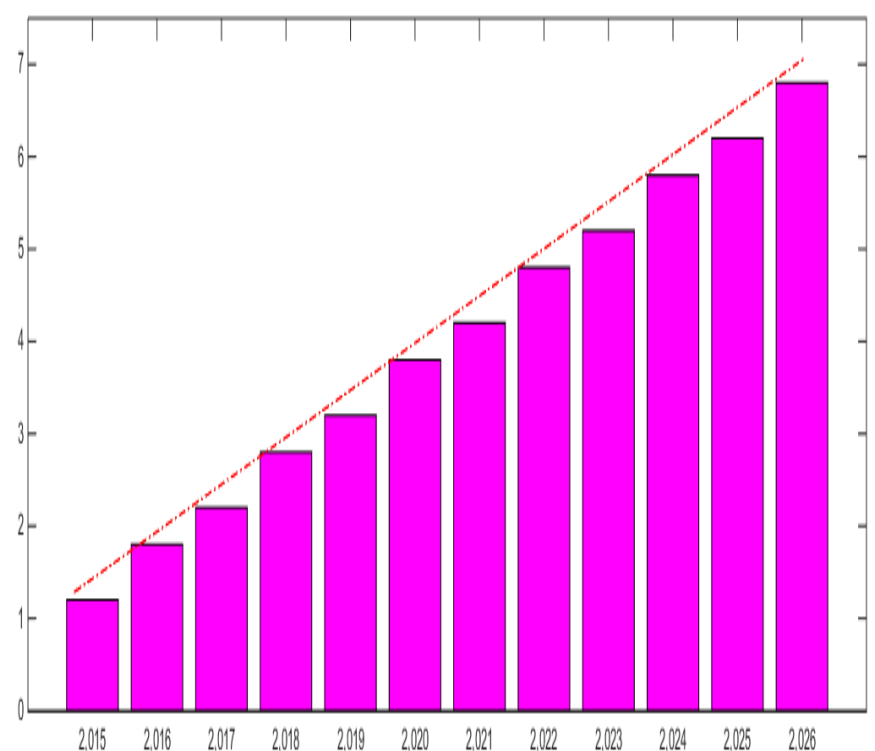

Fig. 11. DT Market 2015-2026.
As illustrated in Fig. 11 based on the statistics collected from [56], the global DT market is expected to reach USD 36.6 billion by 2025, rising at a CAGR of 38.5 percent from 2020 to 2026. Increased acceptance of new technologies such as IoT and cloud, increased demand for connected devices in the automotive and transportation industries, and expanding predictive maintenance usage are all driving market expansion.

\section{E. COBOTS and IR 5.0}

Robots are far superior to humans in the creation of highvolume items and are far more compatible. Robots are inefficient in critical thinking when compared to humans. When robots need to be guided, customizing or personalizing things may be a huge difficulty. As a result, managing human connections within manufacturing processes is critical. COBOTS have a lot of potential in IR 5.0. Robots can achieve their intended aim by collaborating with humans, allowing for the rapid and accurate delivery of mass customized and personalized items to clients [57]. Throughout IR 5.0, personalizing COBOTS may take various forms, including medical treatments. COBOTS aid with the improvement of safety and performance in IR 5.0 applications, while also providing more engaging tasks for human workers and enhancing product development. In highly competitive marketplaces, industries must recognize that COBOTS have the potential to increase corporate performance and minimize rising labor expenses [58]. According to the interact analysis report, material handling, assembly, and pick-and-place are expected to be the three most common uses of collaborative robots in the future [59]. In 2024, these three tasks will account for 62.7 percent of collaborative robot revenues, up from 71.9 percent in 2019 as depicted in Fig. 12. Pick and place is expected to remain the third most popular use for collaborative robots by 2024, according to Interact Analysis, but note the bar on the far right of each graph that denotes "other applications." Innovative COBOTS technologies are positioned to enter a variety of new products and non-manufacturing contexts settings for which industrial robots are unsuitable.

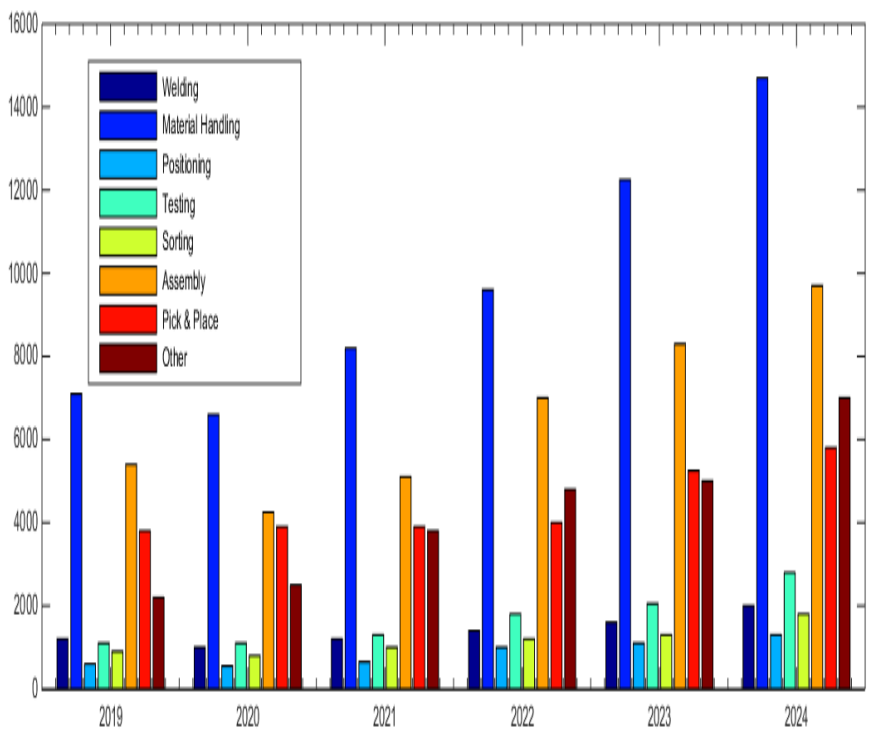

Fig. 12. Prediction of COBOTS Shipment by Application. 


\section{F. $6 G$ \& Beyond and IR 5.0}

Due to the rapid rise of smart infrastructure and prospective applications, it will be impossible to quickly expand bandwidth requirements with present networks. The usage of $6 \mathrm{G}$ and beyond in the IR 5.0 revolution allows for lower latency, highquality services, and vast IoT infrastructure, as well as integrated AI capabilities. 6G networks aid in the efficient and successful execution of IR 5.0 applications by enabling smart spectrum management and smart mobility. 6G networks are intended to satisfy the needs of future society by interconnecting the overall society [60]. IR 5.0 apps have a major challenge in terms of energy management due to a large number of connected smart devices and the significant quantity of energy they use. The employment of advanced energy efficiency algorithms and energy harvesting technology will make 6G networks more energy-efficient [61]. According to the ITU, the exponential growth trend will continue, and global mobile data traffic will reach a staggering 5ZB per month by 2030 [60], as seen in Fig. 13.

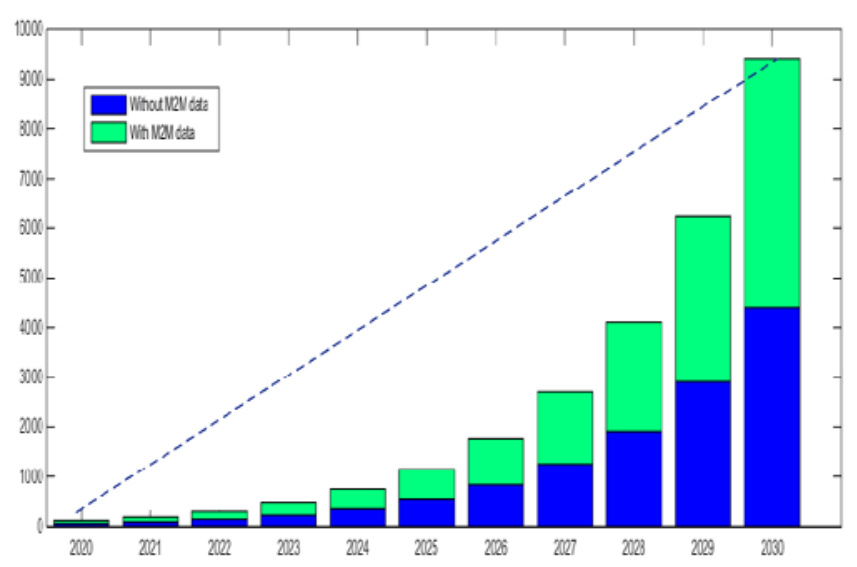

Fig. 13. Global Mobile Data Traffic Forecasting by ITU.

\section{G. Blockchain Technology (BCT) and IR 5.0}

BCT has the potential to provide significant value to IR 5.0 in the future. In IR 5.0, centralized administration of a high number of heterogeneous linked devices is a major difficulty. By enabling distributed trust, BCT may be utilized to construct decentralized and distributed management solutions. For effective subscriber management in IR 5.0, BCT may be utilized to generate digital identities for various persons and businesses. It's required for access management and authentication of stakeholders in any industrial activity that takes place via the internet [62].

Additionally, these digital identities may be used to manage properties, belongings, items, and services. BCT may also be used to catalog and save original work and register IP rights. By automating the agreement procedures between diverse parties, BCT can also assist to automate the contractual process [63]. According to [60], by 2028, the worldwide BCT industry is anticipated to be worth USD 394.60 billion. At the same time, financial institutions' increased interest in BCT is propelling industry expansion. According to [64], the market size of Blockchain is increasing with time as shown in Fig. 14, it shows that BCT is a widely used technology of the current time.

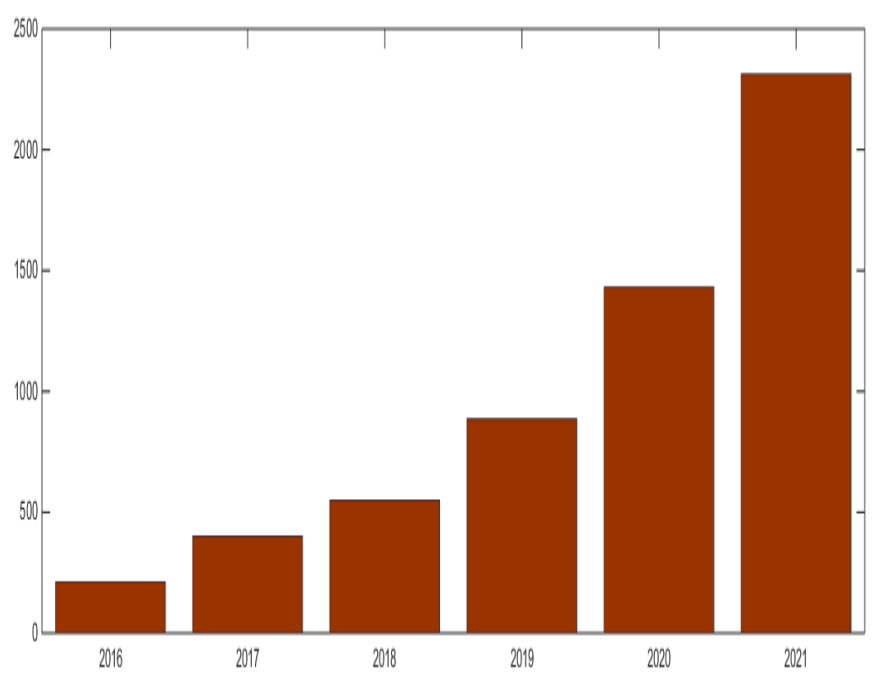

Fig. 14. Blockchain Market Size Worldwide.

\section{H. Other Enabling Technologies}

In addition to the above-discussed technologies, other CET such as EC, network slicing, augmented reality, and 3D printing also plays a vital role in IR 5.0. EC reduces communication costs and ensures that programs run smoothly even at faraway locations. Additionally, EC can process data without sending it to the public cloud, reducing security concerns for IR 5.0's major events [65]. Because IR 5.0 supports a broad collection of applications, a single physical infrastructure will be unable to meet the needs of heterogeneous networks. In this situation, network slicing can provide several virtualized networks at a low cost [66]. The way information is accessed, used, and transferred is changing because of augmented reality. In truth, augmented reality is data that broadens people's perceptions. This technology enhances our sensory perception by allowing us to engage with data. Because augmented reality can actively contribute to the success and transformation of industrial production processes, it will be useful as IR 5.0 focuses on human-machine collaboration [67]. The usage of $3 \mathrm{D}$ technology is increasing in a variety of industries, from food printing to the construction of Mars settlements. Innovations in the healthcare, automotive, construction, and manufacturing sectors are among the more practical applications for 3D printing. The 3D printer is being dubbed the forerunner of the 5th IR by scholars and practitioners for these reasons [68].

\section{CHALLENGES OF IR 5.0}

Despite the benefits offered by IR 5.0, it also faces several challenges. Some of the most significant challenges of IR 5.0, as taken from available research [23-26, 69], are as follows:

1) Initial cost: IR 5.0 necessitates a significant amount of expenditure to completely execute all of its pillars, which is challenging for the industry, particularly SMEs, to accomplish.

2) Lack of precision and accuracy: For example, IR 5.0 has a lot of potential in the healthcare business, but it requires a lot of precision and accuracy. The research in this area is still in its infancy, and it necessitates a significant amount of investment and infrastructure. 
3) Technology requirements: This presents a challenge for startups and entrepreneurs, as IR 5.0 necessitates a significant amount of investment and infrastructure, as well as CET requirements.

4) Skill-gap: This tendency exacerbates job polarization, as middle-skill employment declines and the workforce is divided into two groups: highly trained and qualified personnel and low-paid and unqualified workers. This may help to bridge the gap between the skilled and unskilled in society.

5) Need training: Due to highly automated manufacturing systems, skill development is a massive task that includes training employees to adopt advanced CET as well as inducing behavioral changes to interact with them.

6) Risk: Collaborative robotics is a type of technology that, along with human coworkers, poses a significant risk on the factory floor.

7) Data integration: It is difficult to obtain high quality and integrity data from industrial systems, and it is also challenging to accommodate several data sources.

8) Regulatory system: Due to the high level of automation in IR 5.0, it is difficult to develop regulatory systems. For example, who should be held accountable and to what extent in the event of a failure.

9) Process tailoring: The old company strategy and business models must be adjusted and tailored to match the requirements of IR 5.0 due to a greater degree of automation in the industries.

10)Mass personalization: As a result of mass personalization, company strategy will become more customercentric. Customer subjectivity shifts throughout time, making it tough to adapt corporate strategies and models regularly.

\section{DISCUSSION}

Humans have recognized the possibility of using technology as a tool of advancement since the first IR. Steam machines, assembly lines, and computers are just a few of the technological developments that have occurred over the previous several centuries, all with the goal of producing more powerful technology and enhancing productivity and effectiveness. IR 5.0 shifts the paradigm and ushers in a revolution by putting less emphasis on technology and assuming that the ultimate potential for advancement resides in human-machine cooperation. IR 5.0 is not a passing trend, but rather it's a manufacturing paradigm change with ramifications for productivity, economics, and commerce. Due to the competitive benefits that the IR 5.0 model offers, organizations that do not adapt their production to this model will quickly become outdated.

IR 5.0 acknowledges that industry can fulfill social objectives beyond employment and development, such as becoming a dependable source of wealth, by making sure that production takes into account the limitations of our planet and places a premium on the well-being of industry employees. Keeping in view the benefits of IR 5.0, this study provides a full description of IR 5.0, as well as the functions of CET, so that scholars and practitioners may appreciate the significance of this revolution and recommend ways for maximizing its benefits.

\section{CONCLUSION}

IR 5.0 expands on the established IR 4.0 paradigm by placing a premium on research and innovation as critical drivers of the transition to a better industry. It refocuses attention on stakeholder value, which helps everyone. It places a premium on worker well-being throughout the manufacturing process and leverages new technologies to create wealth beyond employment and development, all while keeping conscious of the planet's production restrictions. In the upcoming days, the industries which will not follow IR 5.0 will obsolete from the market. Keeping in view the importance of IR 5.0, this conceptual paper provides a detailed overview of IR 5.0. The key topics covered in this research article include: providing a comprehensive knowledge of the IR 5.0 concept from several angles, promising applications of IR 5.0, the role of modern CET in the fifth IR, and opportunities and challenges faced by IR 5.0. This paper will help researchers and industry practitioners to better understand the role of IR 5.0 in the upcoming era.

CET's involvement in real-time IR 5.0 settings will be further examined in the future. Additionally, we'll combine human expertise with CET to study the real-world effects of IR 5.0.

\section{ACKNOWLEDGMENT}

The author would like to acknowledge the support provided by the Deanship of Scientific Research at Jouf University, Saudi Arabia.

REFERENCES

[1] Humayun, M., Industry 4.0 and Cyber Security Issues and Challenges. Turkish Journal of Computer and Mathematics Education (TURCOMAT), 2021. 12(10): p. 2957-2971.

[2] Humayun, M., et al., Privacy protection and energy optimization for 5Gaided industrial Internet of Things. IEEE Access, 2020. 8: p. 183665183677.

[3] Ragulina, Y.V., et al., Methodology of criterial evaluation of consequences of the industrial revolution of the 21st century, in Industry 4.0: Industrial Revolution of the 21st Century. 2019, Springer. p. 235244.

[4] Nahavandi, S., Industry 5.0—A human-centric solution. Sustainability, 2019. 11(16): p. 4371.

[5] Alferidah, Dhuha Khalid, and N. Z. Jhanjhi. "Cybersecurity Impact over Bigdata and IoT Growth." In 2020 International Conference on Computational Intelligence (ICCI), pp. 103-108. IEEE, 2020.

[6] Almusaylim, Zahrah A., and Noor Zaman. "A review on smart home present state and challenges: linked to context-awareness internet of things (IoT)." Wireless networks 25, no. 6 (2019): 3193-3204.

[7] Leong, Y.K., et al., Significance of industry 5.0, in The Prospect of Industry 5.0 in Biomanufacturing. 2021, CRC Press. p. 95-114.

[8] Demir, K.A., G. Döven, and B. Sezen, Industry 5.0 and human-robot coworking. Procedia computer science, 2019. 158: p. 688-695.

[9] Xu, X., et al., Industry 4.0 and Industry 5.0-Inception, conception and perception. Journal of Manufacturing Systems, 2021. 61: p. 530-535.

[10] Maddikunta, P.K.R., et al., Industry 5.0: a survey on enabling technologies and potential applications. Journal of Industrial Information Integration, 2021: p. 100257.

[11] Chai, Y.H., et al., State-of-the-Art Technologies in Industry 5.0, in The Prospect of Industry 5.0 in Biomanufacturing. 2021, CRC Press. p. 257286. 
[12] Li, J.-Q., et al., Industrial internet: A survey on the enabling technologies, applications, and challenges. IEEE Communications Surveys \& Tutorials, 2017. 19(3): p. 1504-1526.

[13] Ruppert, T., et al., Enabling technologies for operator 4.0: A survey. Applied Sciences, 2018. 8(9): p. 1650.

[14] Martinelli, A., A. Mina, and M. Moggi, The enabling technologies of industry 4.0: Examining the seeds of the fourth industrial revolution. Industrial and Corporate Change, 2021. 30(1): p. 161-188.

[15] Knudsen, M.S., J. Kaivo-oja, and T. Lauraeus. Enabling Technologies of Industry 4.0 and Their Global Forerunners: An Empirical Study of the Web of Science Database. in International Conference on Knowledge Management in Organizations. 2019. Springer.

[16] Hu, M., et al., Virtual reality: A survey of enabling technologies and its applications in IoT. Journal of Network and Computer Applications, 2021: p. 102970.

[17] Longo, F., A. Padovano, and S. Umbrello, Value-oriented and ethical technology engineering in industry 5.0: a human-centric perspective for the design of the factory of the future. Applied Sciences, 2020. 10(12): p. 4182.

[18] Sułkowski, Ł., Kolasińska-Morawska, K., Seliga, R. and Morawski, P., 2021. Smart Learning Technologization in the Economy 5.0-The Polish Perspective. Applied Sciences, 11(11), p.5261.

[19] Farsi, M., R.K. Mishra, and J.A. Erkoyuncu, Industry 5.0 for Sustainable Reliability Centered Maintenance. Available at SSRN 3944533, 2021.

[20] Aslam, F., et al., Innovation in the era of IoT and industry 5.0: absolute innovation management (AIM) framework. Information, 2020. 11(2): p. 124.

[21] Rachmawati, I., et al., Prevalence of Academic Resilience of Social Science Students in Facing the Industry 5.0 Era. International Journal of Evaluation and Research in Education, 2021. 10(2): p. 676-683.

[22] Al Faruqi, U., Future Service in Industry 5.0. Jurnal Sistem Cerdas, 2019. 2(1): p. 67-79.

[23] ElFar, O.A., et al., Prospects of Industry 5.0 in algae: Customization of production and new advance technology for clean bioenergy generation. Energy Conversion and Management: X, 2021. 10: p. 100048.

[24] Paschek, D., A. Mocan, and A. Draghici. Industry 5.0-The expected impact of next Industrial Revolution. in Thriving on Future Education, Industry, Business, and Society, Proceedings of the MakeLearn and TIIM International Conference, Piran, Slovenia. 2019.

[25] Skobelev, P. and S.Y. Borovik, On the way from Industry 4.0 to Industry 5.0: From digital manufacturing to digital society. Industry 4.0, 2017. 2(6): p. 307-311.

[26] Ngo, L., The influence of ICT on the accommodation industry in the upcoming industry 5.0. 2019.

[27] Lasi, H., Fettke, P., Kemper, H.G., Feld, T. and Hoffmann, M., 2014. Industry 4.0. Business \& information systems engineering, 6(4), pp.239242.

[28] Potočan, V., M. Mulej, and Z. Nedelko, Society 5.0: Balancing of Industry 4.0, economic advancement and social problems. Kybernetes, 2020.

[29] Zengin, Y., et al., An investigation upon industry 4.0 and society 5.0 within the context of sustainable development goals. Sustainability, 2021. 13(5): p. 2682.

[30] Polat, L. and A. Erkollar. Industry 4.0 vs. Society 5.0. in The International Symposium for Production Research. 2020. Springer.

[31] Javaid, M., et al., Industry 5.0: Potential applications in COVID-19. Journal of Industrial Integration and Management, 2020. 5(04): p. 507530.

[32] Ullah, A., et al., Secure healthcare data aggregation and transmission in IoT-A survey. IEEE Access, 2021. 9: p. 16849-16865.

[33] Irujo Aizcorbe, J., A review on human robot collaboration and its application in the health care sector. 2020.

[34] Gong, B., Nugent, J.P., Guest, W., Parker, W., Chang, P.J., Khosa, F. and Nicolaou, S., 2019. Influence of artificial intelligence on Canadian medical students' preference for radiology specialty: ANational survey study. Academic radiology, 26(4), pp.566-577.
[35] Majid, Mahardhika Ishlah, Cattleya Khansa Darmawan, Suharto Abdul Majid, and Yuda Yulianto. "Anticipating the Entry of Industry 5.0 in Transportation Sector." Advances in Transportation and Logistics Research 2 (2019): 103-115.

[36] Leea, Wen - Chieh, and Shinn-Shyr Wangb. "Misallocations and Policy Constraints on Mergers in the Modern Manufacturing Sector."

[37] Rupa, C., Midhunchakkaravarthy, D., Hasan, M.K., Alhumyani, H. and Saeed, R.A., 2021. Industry 5.0: Ethereum blockchain technology based DApp smart contract. Mathematical Biosciences and Engineering, 18(5), pp.7010-7027.

[38] Frederico, G.F., From Supply Chain 4.0 to Supply Chain 5.0: Findings from a Systematic Literature Review and Research Directions. Logistics, 2021. 5(3): p. 49.

[39] Taranenko, N.Y., et al., Education as socio-cultural and economic potential of the global information society. Journal of History Culture and Art Research, 2019. 8(1): p. 136-145.

[40] Saxena, A., et al., Emergence of Educators for Industry 5.0-An Indological Perspective.

[41] Begum, Salma. "A Study on growth in Technology and Innovation across the globe in the Field of Education and Business." International Research Journal on Advanced Science Hub 3 (2021): 148-156.

[42] https://www.statista.com/statistics/1200006/industry-40-technologygreatest-impact-organizations-worldwide/.

[43] Ullah, A., et al., Secure Critical Data Reclamation Scheme for Isolated Clusters in IoT enabled WSN. IEEE Internet of Things Journal, 2021.

[44] Alkinani, M.H., et al., 5G and IoT Based Reporting and Accident Detection (RAD) System to Deliver First Aid Box Using Unmanned Aerial Vehicle. Sensors, 2021. 21(20): p. 6905.

[45] Özdemir, V. and N. Hekim, Birth of industry 5.0: Making sense of big data with artificial intelligence,"the internet of things" and nextgeneration technology policy. Omics: a journal of integrative biology, 2018. 22(1): p. 65-76.

[46] Alam, T., A reliable communication framework and its use in internet of things (IoT). CSEIT1835111| Received, 2018. 10: p. 450-456.

[47] Humayun, M., Role of emerging IoT big data and cloud computing for real time application. Int. J. Adv. Comput. Sci. Appl., 2020. 11(4): p. 113.

[48] Mishra, S.K., et al., Energy-aware task allocation for multi-cloud networks. IEEE Access, 2020. 8: p. 178825-178834.

[49] Alayda, S., et al., A Novel Hybrid Approach for Access Control in Cloud Computing.

[50] Islam, T. and HASAN, M., 2017. A Performance Analysis of a Typical Server running on a Cloud.

[51] Fukuda, K., Science, technology and innovation ecosystem transformation toward society 5.0. International journal of production economics, 2020. 220: p. 107460.

[52] Majeed, A., et al., A big data-driven framework for sustainable and smart additive manufacturing. Robotics and Computer-Integrated Manufacturing, 2021. 67: p. 102026.

[53] Gagan, B. R., S. K. Majumdar, and S. Menon. "Application of Data Science in Transforming the Digital Economy: Evidence From Global Big Data Analytics Service Providers." In 2nd International Conference on Digital Entrepreneurship (ICDE 2019) Conference Proceedings, Bangalore, India (8, vol. 9, p. 2.

[54] Fei, T., et al., Digital twin-driven product design, manufacturing and service with big data. The International Journal of Advanced Manufacturing Technology, 2018. 94(9-12): p. 3563-3576.

[55] Teng, S.Y., et al., Recent advances on industrial data-driven energy savings: Digital twins and infrastructures. Renewable and Sustainable Energy Reviews, 2021. 135: p. 110208.

[56] Zubarev, A. E., O. V. Vatolina, and A. M. Kolesnikov. "Information And Communication Technologies Of Digital Transformation Of The Economy." In European Proceedings of Social and Behavioural Sciences EpSBS, pp. 435-442. 2020.

[57] Simões, A.C., A.L. Soares, and A.C. Barros, Factors influencing the intention of managers to adopt collaborative robots (cobots) in 
manufacturing organizations. Journal of Engineering and Technology Management, 2020. 57: p. 101574.

[58] Sowa, K., A. Przegalinska, and L. Ciechanowski, Cobots in knowledge work: Human-AI collaboration in managerial professions. Journal of Business Research, 2021. 125: p. 135-142.

[59] Calitz, Andre P., Paul Poisat, and Margaret Cullen. "The future African workplace: The use of collaborative robots in manufacturing." SA Journal of Human Resource Management 15, no. 1 (2017): 1-11.

[60] Tariq, F., et al., A speculative study on 6G. IEEE Wireless Communications, 2020. 27(4): p. 118-125.

[61] Lu, Y. and X. Zheng, 6G: A survey on technologies, scenarios, challenges, and the related issues. Journal of Industrial Information Integration, 2020: p. 100158.

[62] Alamri, M., Jhanjhi, N.Z. and Humayun, M., 2019. Blockchain for Internet of Things (IoT) research issues challenges \& future directions: A review. Int. J. Comput. Sci. Netw. Secur, 19, pp.244-258.

[63] Humayun, M., Jhanjhi, N.Z., Hamid, B. and Ahmed, G., 2020. Emerging smart logistics and transportation using IoT and blockchain. IEEE Internet of Things Magazine, 3(2), pp.58-62.
[64] Singh, A.P., Pradhan, N.R., Luhach, A.K., Agnihotri, S., Jhanjhi, N.Z., Verma, S., Ghosh, U. and Roy, D.S., 2020. A novel patient-centric architectural framework for blockchain-enabled healthcare applications. IEEE Transactions on Industrial Informatics, 17(8), pp.5779-5789.

[65] Du, A., et al., CRACAU: Byzantine Machine Learning meets Industrial Edge Computing in Industry 5.0. IEEE Transactions on Industrial Informatics, 2021.

[66] Xu, L., et al., AF Relaying Secrecy Performance Prediction for 6G Mobile Communication Networks in Industry 5.0. IEEE Transactions on Industrial Informatics, 2021.

[67] Ramalho, F. and A.L. Soares, Augmented reality in complex manufacturing systems as an informational problem: a human-centered approach. iConference 2020 Proceedings, 2020.

[68] Martynov, V.V., D.N. Shavaleeva, and A.A. Zaytseva. Information Technology as the Basis for Transformation into a Digital Society and Industry 5.0. in 2019 International Conference" Quality Management, Transport and Information Security, Information Technologies"(IT\&QM\&IS). 2019. IEEE.

[69] Zambon, I., et al., Revolution 4.0: Industry vs. agriculture in a future development for SMEs. Processes, 2019. 7(1): p. 36. 